\title{
Impact of rheumatoid arthritis on the quality of life and its relation to disease activity
}

\author{
Samar H. Goma, Mohamed Raouf Abdel Razek, Nesreen M. Abdelbary
}

Department of Physical Medicine

Rheumatology and Rehabilitation, Assiut

University Hospitals, Assiut, Egypt

Correspondence to Samar H. Goma,

Department of Physical Medicine,

Rheumatology and Rehabilitation, Assiut

University Hospitals, Assiut, 71515, Egypt

e-mail: samarhassanein2010@yahoo.com

Received 1 May 2019

Accepted 21 June 2019

Egyptian Rheumatology \& Rehabilitation 2019, 46:304-312

\begin{abstract}
Background
Quality of life (QOL) is a multidimensional concept that is used to describe the individuals' perceptions, satisfaction, and evaluation of different areas of their own lives, such as physical health and functioning, psychological and emotional wellbeing, social roles, and relationships. Few studies have addressed the effect of rheumatoid disease on the QOL in the Egyptian community.

Results

Functional disability based on health assessment questionnaire disability index was significantly increased with the increase in disease activity based on disease activity score-28, where all patients on remission and $56 \%$ of those with low disease activity had mild functional disability. Approximately $89 \%$ of patients with low disease activity had mild anxiety based on Hamilton anxiety scale, and the majority $(75 \%)$ of those patients with moderate disease activity and $83.3 \%$ of patients on remission had mild anxiety. The majority (85.7\%) of those with high disease activity were depressed based on Zung self-rating depression score.

Disease activity score-28 score had a positive significant correlation with health assessment questionnaire disability index $(P=0.01, r=0.40)$, Hamilton anxiety scale-A $(P=0.01, r=0.46)$, Zung score $(P=0.01, r=0.46)$, and rheumatoid arthritis $\mathrm{QOL}(r=0.70, P=0.00)$, and negative correlation with female sexual index ( $r=-0.80$, $P=0.00$ ), all domains of SF-36, and all five domains of WHOQOL.

\section{Conclusion}

This study confirms that rheumatoid arthritis causes impairment of all aspects of QOL (limitation of physical function, physical disability, and pain), mental health disorders (anxiety and depression), and social, environmental, and also sexual dysfunction.
\end{abstract}

\section{Keywords:}

disease activity score, quality of life, rheumatoid arthritis

Egypt Rheumatol Rehabil 46:304-312

(C) 2019 Egyptian Society for Rheumatology and Rehabilitation

$1110-161 \mathrm{X}$

\section{Introduction}

Rheumatoid arthritis (RA) is an autoimmune progressive disease affecting $\sim 1 \%$ of the general population [1]. It is mainly a disease of the joints resulting in destruction of the joints and disability, and in severe cases, it may cause life-threatening complications [2]. Musculoskeletal disorders are considered the second largest cause of disability globally, second but close only to behavioral and mental disorders [3]. Many terms are used [e.g. quality of life (QOL), health status, health-related QOL] to discuss the effect of diseases, such as arthritis, on functioning and sense of well-being. At the broadest level, QOL refers not only to health status but also to environmental and economic factors (e.g. income and educational attainment) that can substantially influence well-being. Thus, different conceptual frameworks guide how QOL is defined and measured [4]. QOL is important for measuring the effect of the disease, and for evaluating the effects and cost-effectiveness of the treatment. Some studies have assessed the QOL in patients with RA and its improvement with early treatment [5]. Owing to medical treatment and health care, QOL became more important, as it extends length of life, sometimes at the expense of QOL, or improve QOL, without extending length of life [6]. RA has major diverse effects on patients' QOL, affecting both mental and physical domains of well-being [7]. QOL is defined as the general well-being of individuals and societies, based on the individual's culture and life values with respect to that individual's objectives, expectation, and standards. It is an important outcome variable in patients with chronic diseases. It also reflects the influences of the personal social and economic resources that an individual has and the way in which these interact with health status. So, QOL can be defined as awareness of people about life, standards, goals, values, and interests [8]. The

This is an open access journal, and articles are distributed under the terms of the Creative Commons Attribution-NonCommercial-ShareAlike 4.0 License, which allows others to remix, tweak, and build upon the work non-commercially, as long as appropriate credit is given and the new creations are licensed under the identical terms. 
physical disability caused by RA is usually detected clinically; however, the psychological and social morbidities can be easily missed by the clinician [9] Patients with RA report reduced QOL in several aspects, such as level of independence, physical health, environment, and personal beliefs, compared with the healthy population [10]. Generic and diseasespecific QOL scales have been used for evaluating QOL in RA. Disease-specific scales have been designed to pick up health-related aspects particular to the specific disease and that is why they have advantages over the generic ones. They are also more effective than generic instruments to assess treatment response $[11,12]$.

The aim of this study is to assess the QOL in RA and its association with disease activity.

\section{Patients and methods}

A cross-sectional study where 50 patients diagnosed as having RA according to 2010 ACR criteria (RA classification criteria) [13] were enrolled in the study. All patients were from those who attended the Physical Medicine, Rheumatology and Rehabilitation Department and Outpatient Clinic, at Assiut University Hospitals, in the period between September 2016 and March 2018.

\section{Inclusion criteria}

The following were the inclusion criteria:

(1) Patients diagnosed as having RA according to 2010 ACR criteria.

(2) Patients more than 18 years.

\section{Exclusion criteria}

The following were the exclusion criteria:

(1) Bedridden patients.

(2) Presence of significant comorbidity such as malignancies or end-stage organ failure.

(3) Pregnant women.

(4) Other rheumatic diseases.

The research was approved by Assiut medical colleague ethics committee for research, keeping patient confidentiality and safety. Verbal and written consents were taken from patients.

For 50 patients with RA, a checklist containing questions on demographic data include age, sex, marital status, level of education, occupation, and cardiovascular comorbidities were completed for all patients.
Full investigations had been done including complete blood count, erythrocyte sedimentation rate, rheumatoid factor, and liver and kidney function tests. Disease activity score (DAS) had been assessed through DAS-28 by erythrocyte sedimentation rate. A DAS-28 score of higher than 5.1 was indicative of high disease activity, whereas a DAS-28 below 3.2 indicated low disease activity. A patient was considered to be in remission if they had a DAS-28 lower than 2.6.

All patients with RA completed all the following questionnaires.

(1) The health assessment questionnaire disability index (HAQ-DI)

The following categories are assessed by the HAQ-DI: dressing and grooming, arising, eating, walking, hygiene, reach, grip, and common daily activities. The patients are asked about the degree of difficulty they have in performing these activities. The answers were on a scale ranging from 0 to 3 where if the activity can be performed without any difficulty (scale 0 ) up to cannot be done at all (scale 3). The HAQ-DI is usually analyzed by calculating scores. In each dimension (dressing and grooming, arising, eating, walking, hygiene, reach, grip, and activities), the raw score is calculated as Max (dimension score) and corrected if aids and devices were used or help from another person was needed. This correction will raise a raw score of 0 or 1 to a 2 and will remain as raw score in all other cases.

(2) The Hamilton anxiety scale (HAM-A)

The scale consists of 14 items assessing both psychic anxiety (mental agitation and psychological distress) and somatic anxiety (physical complaints related to anxiety). The HAM-A has been questioned for its sometimes poor ability to differentiate between anxiolytic and antidepressant effects, and somatic anxiety versus somatic side effects. Regardless of this, the reported levels of reliability for the scale appear to be acceptable.

Scoring was done as follows: each item is scored on a scale of 0 (not present) to 4 (severe), with a total score range of $0-56$, where less than 17 indicates mild severity, 18-24 mild to moderate severity, and 25-30 moderate to severe.

(3) The Zung Self-Rating Depression Scale is a short self-administered survey to assess the status of depression of a patient. There are 20 items on the scale that assess the affective, psychological, and somatic symptoms associated with depression. There are ten positively worded and ten negatively 
worded questions. Each question is scored on a scale of 1 through 4 (based on these replies: 'a little of the time', 'some of the time', 'good part of the time', and 'most of the time'). The scores range from 25 to 100: 25-49 normal range, 50-59 mildly depressed, 60-69 moderately depressed, and 70 and above severely depressed.

(4) The rheumatoid arthritis quality of life questionnaire (RAQOL) consists of 30 items with a yes or no ( 1 or 0$)$ response. The overall score is the sum of the individual item scores, with a lower score indicating better QOL (range: $0-30$ ).

(5) The Female Sexual Function Index (FSFI): a multidimensional self-report instrument for the assessment of female sexual function was used to investigate problems with sexual functioning during the past 4 weeks. The FSFI is a 19 -item self-report questionnaire that measures six dimensions of female sexual functioning: desire, arousal, lubrication, orgasm, satisfaction, and pain. The FSFI provides an overall score. The questionnaire was psychometrically further evaluated by Wiegel, Meston, and Rosen, and a diagnostic cutoff score was developed for differentiating women with and without sexual dysfunction. This optimal cutoff point was found to be a Total-FSFI score of 26.55 (Wiegel, 2005 \#63). We decided to use this cutoff score to estimate the portions of participants with sexual dysfunction. There were no cutoff limits available for the different subscales of the questionnaire. Low scores on FSFI indicate more problems with sexual functioning and high scores indicate fewer problems with sexual functioning.

(6) SF-36 is a generic multidimensional measure of QOL that contains eight subscales representing physical functioning, social functioning, role limitations owing to physical health problems, role limitations attributable to emotional problems, mental health, vitality, bodily pain, and general health perceptions. Higher scores of each subscale (which range from 0 to 100) indicate a better QOL. The physical and mental components of the eight scales are combined into physical (PCS) and mental (MCS) component summary scale scores.

(7) The WHOQOL-BREF:

It represents four domain scores, which are physical, psychological, social relations, and environmental, along with two individually scored items about an individual's overall perception of QOL and health. The four domain scores are scaled (0-100) in a positive direction, with higher scores indicating a higher QOL.

\section{Statistical analysis}

Data were collected and analyzed using statistical package for the social sciences (SPSS, version 20; IBM, Armonk, New York, USA). Continuous data were expressed in form of mean \pm SD or median (109), whereas nominal data were expressed in the form of frequency (percentage). $\chi^{2}$-Test was used to compare the nominal data of different groups in the study whereas Student $t$-test was used to compare the mean of two different groups and analysis of variance test for more than two groups.

Pearson correlation was used to determine the correlation between DAS-28 and other continuous variables in the study. $P$ value was significant if less than 0.05 .

\section{Results}

The age of patients with RA ranged between 21 and 67 years, with a mean of $43 \pm 12.45$ years. Of them, 46 (92\%) patients were females and four (8\%) patients were males. Regarding the marital status, 31 (62\%), 10 (20\%), and nine (18\%) patients were married, divorced, and single, respectively. The disease duration ranged from 2 to 15 years, with a mean of $7.06 \pm 4.41$ years. Disease activity ranged from 1.80 to 7.80 , with a mean DAS-28 of $4.28 \pm 1.62$. Based on DAS-28, low activity, moderate activity, and high activity presented in 11 (22\%), 17 (34\%), and 14 $(28 \%)$ patients, respectively, whereas remission presented in eight (16\%) patients.

\section{Relation between disease activity score-28 and health assessment questionnaire disability index in patients with rheumatoid arthritis}

It was noticed that degree of functional disability based on HAQ-DI was significantly increased with the increase in disease activity based on DAS-28, where all patients on remission and $56 \%$ of those with low disease activity had mild functional disability. Moreover, it was noticed that 25 and $16.7 \%$ of patients with high activity had moderate to severe and severe to very severe disability based on HAQDI, respectively. DAS-28 score had positive moderate significant correlation with HAQ-DI $(P=0.01$, $r=0.40$; Fig. 1).

\section{Relation between disease activity score-28 and Hamilton anxiety scale-A in patients with rheumatoid arthritis}

It was noticed that $89 \%$ of patients with low disease activity had mild anxiety based on HAM-A and the majority $(75 \%)$ of those patients with moderate disease activity and $83.3 \%$ of patients on remission had mild 


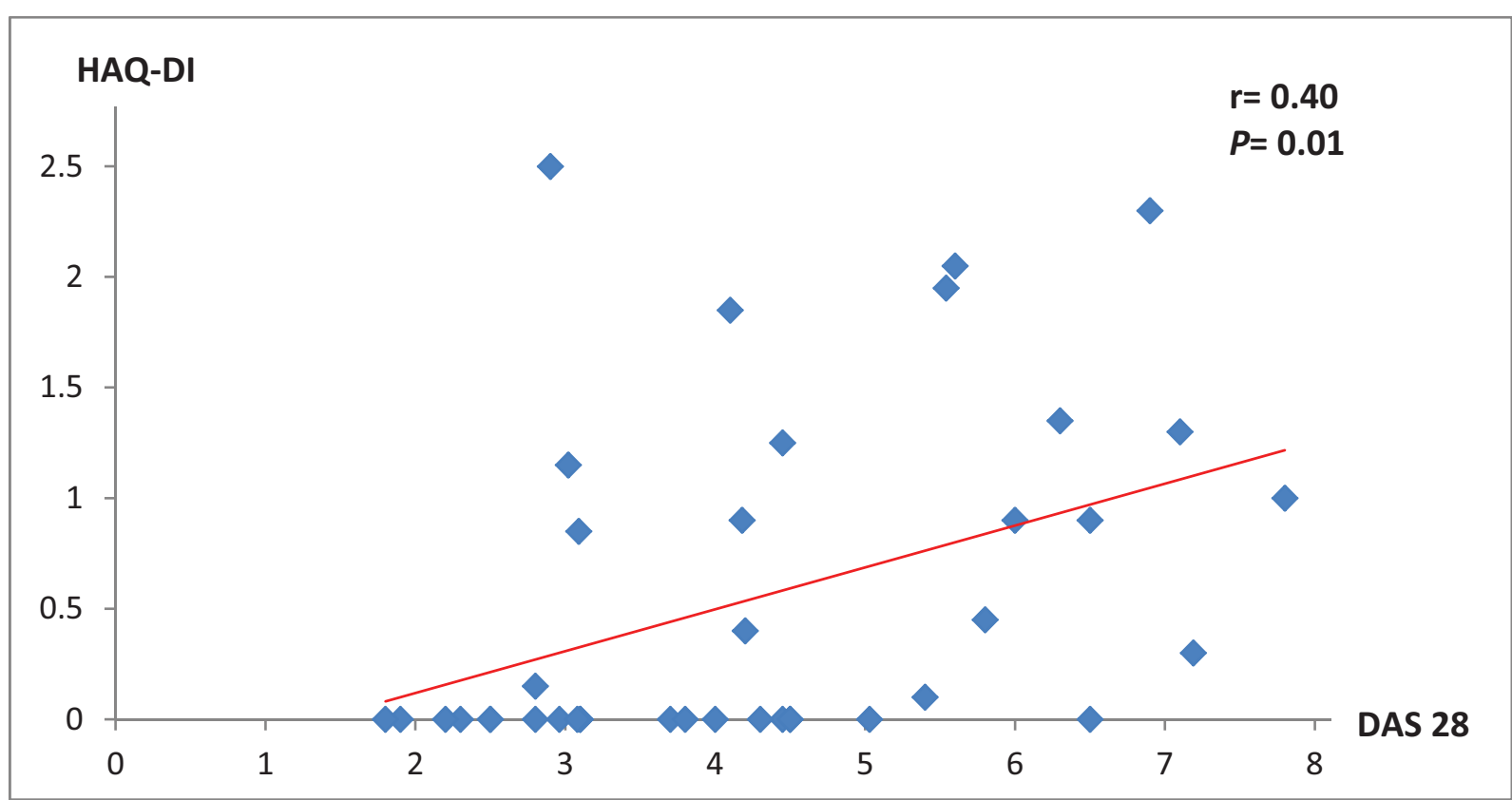

Correlation of disease activity score (DAS)-28 and health assessment questionnaire-disability index (HAQ-DI) in patients with rheumatoid arthritis (RA).

anxiety. DAS-28 score had a positive moderate significant correlation with HAM-A $(P=0.01$, $r=0.46$; Fig. 2).

\section{Relation between disease activity score-28 and Zung} self-rating depression score

Majority of patients with low disease activity (82\%) and those with moderate disease activity $(71 \%)$ were not depressed whereas majority (85.7\%) of those with high disease activity were depressed based on Zung selfrating depression score. DAS-28 score had a positive strong significant correlation with Zung score $(P=0.01$, $r=0.46$; Fig. 3).

\section{Relation between disease activity score-28 and} rheumatoid arthritis quality of life score

It was noticed that DAS-28 has a significant strong positive correlation with RAQOL $(r=0.70, P=0.00$; Fig. 4).

\section{Relation between disease activity score-28 and female sexual function index in patients with rheumatoid arthritis}

It was noticed that DAS-28 has a significant strong negative correlation with female sexual index $(r=-0.80$, $P=0.00)$. Of 46 female patients with RA, 10 (21.7\%) had sexual dysfunction according to FSFI (Fig. 5).

\section{Correlation of disease activity score 28 with domains of SF-36}

It was noticed that all domains of SF-36 had significant negative correlations with DAS-28 in this study. The most affected domain is pain and role limitation owing to physical health. PCS includes physical function, role limitation due to physical health, bodily pain, and general health perception. MCS includes role limitation owing to emotional problems, energy/ fatigue, emotional well-being, and social function. So it was noticed that RA affected PCS more than MCS (Table 1).

Correlation of disease activity score 28 with domains of WHO quality of life in patients with rheumatoid arthritis

It was noticed that all five domains of WHO QOL (general health, physical health, psychological health, social relations, and environmental relations) had significant negative correlations with DAS-28 in this study $(P<0.001$; Table 2$)$.

\section{Discussion}

$\mathrm{RA}$ is a chronic multisystem autoimmune inflammatory disease of unknown etiology that affects $0.5-1 \%$ of the general population. It causes erosion of the joints which is bilateral and symmetrical pattern, causing articular damage, multiple comorbidities, disability, and depressive symptoms [14-17]. RA has a major, diverse effect on patients' QOL, both physical and mental wellbeing [7]. The physical disability is usually obvious by clinical examination; however, the psychological and social morbidities can be missed by the clinician [9] 
Figure 2

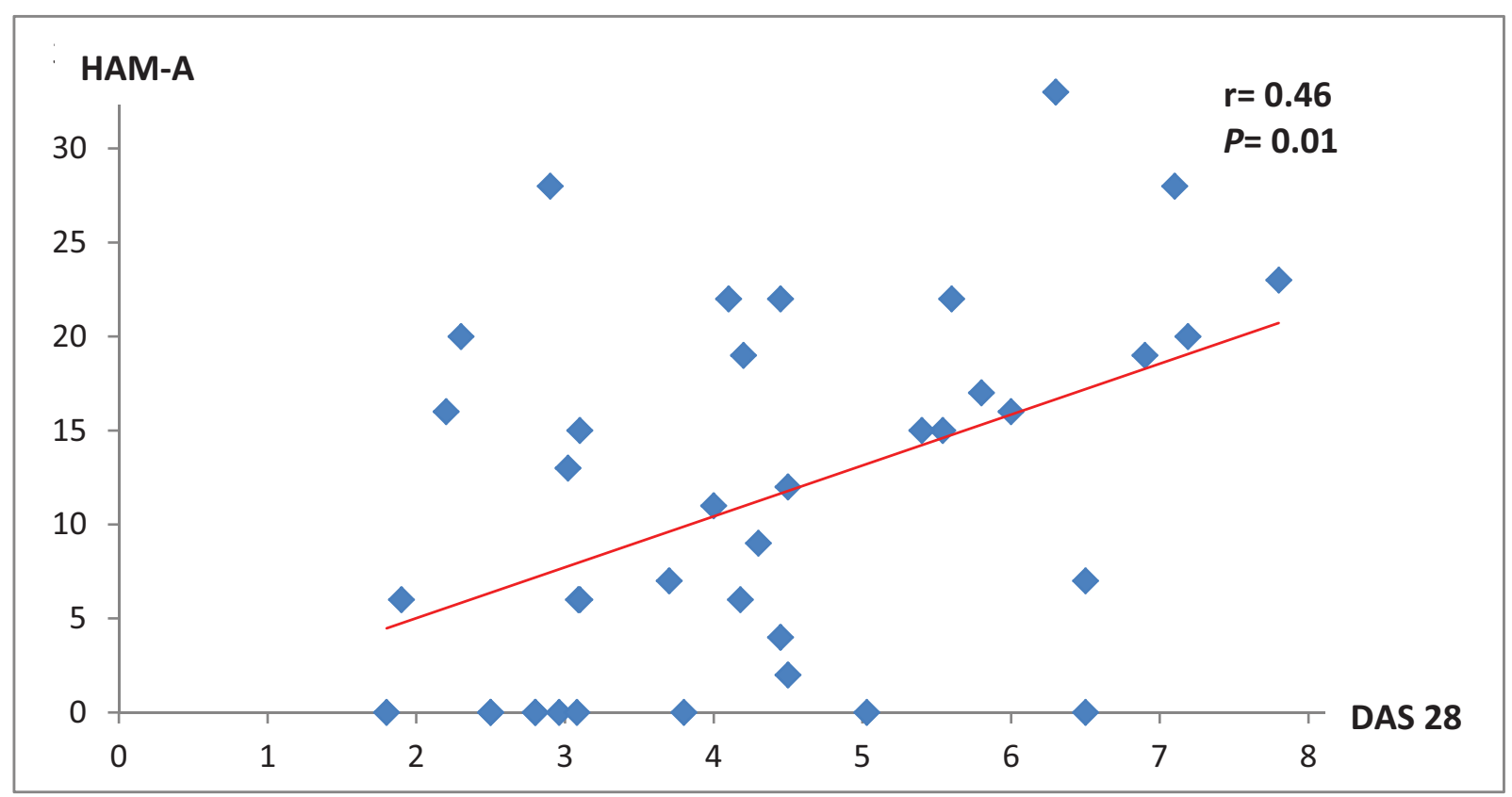

Correlation of disease activity score (DAS)-28 and Hamilton anxiety scale (HAM-A) in patients with rheumatoid arthritis (RA).

Figure 3

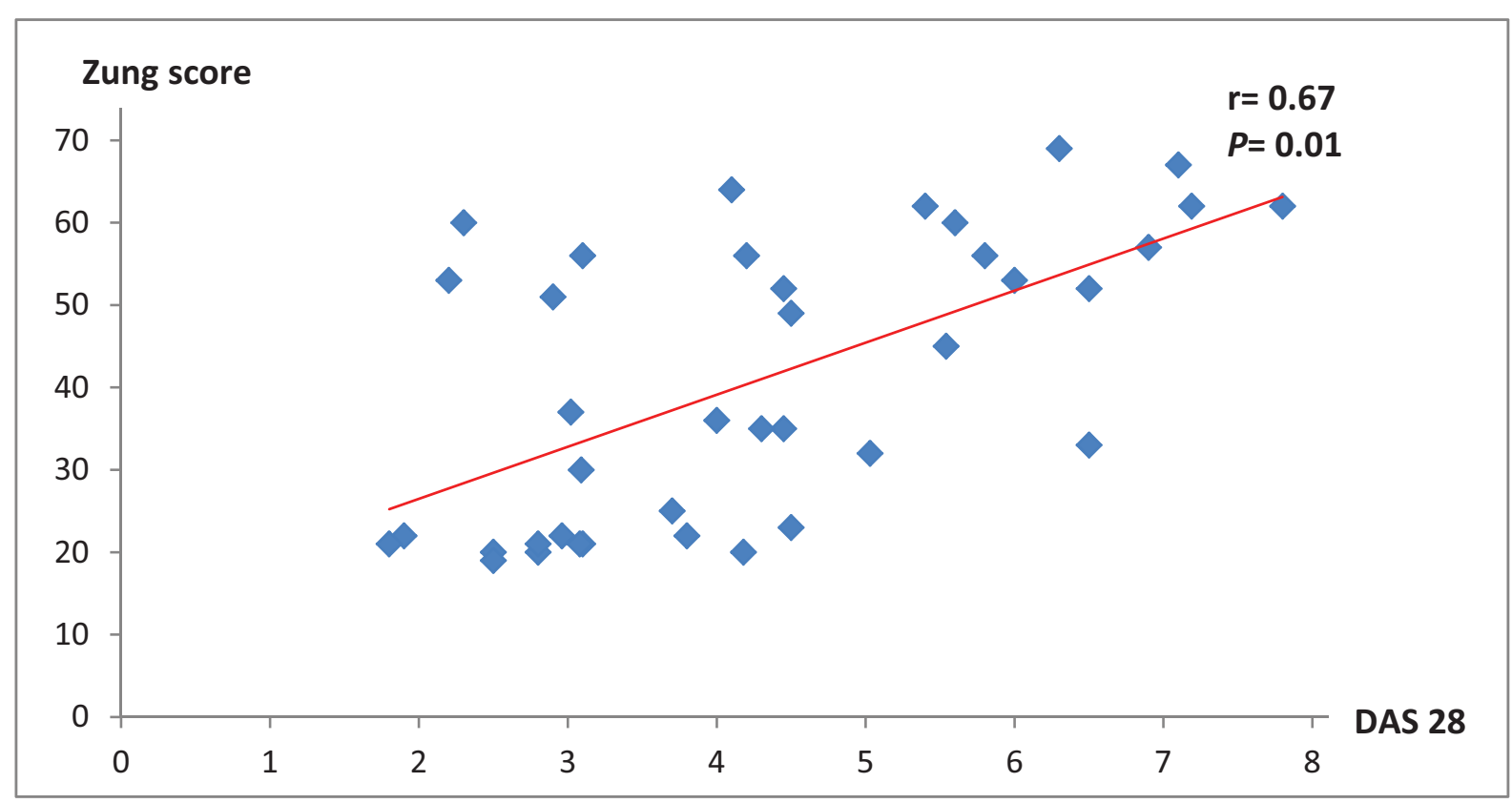

Correlation of disease activity score (DAS)-28 and Zung self-rating depression score in patients with rheumatoid arthritis (RA).

The aim of this study was to assess the QOL in RA and to correlate QOL with disease activity by using different types of generic and specific questionnaires.

This study found that degree of functional disability based on HAQ-DI was significantly increased with the increase in disease activity based on DAS-28, whereas patients on remission and $56 \%$ of those with low disease activity had mild difficulty and $41.7 \%$ of patients with high activity had moderate to severe functional disability based on HAQ-DI, respectively.

This is consistent with the study by Karpouzas et al. [18] that provided evidence that functional disability was common in Chinese patients with RA; this study found that the risk of functional disability increases 

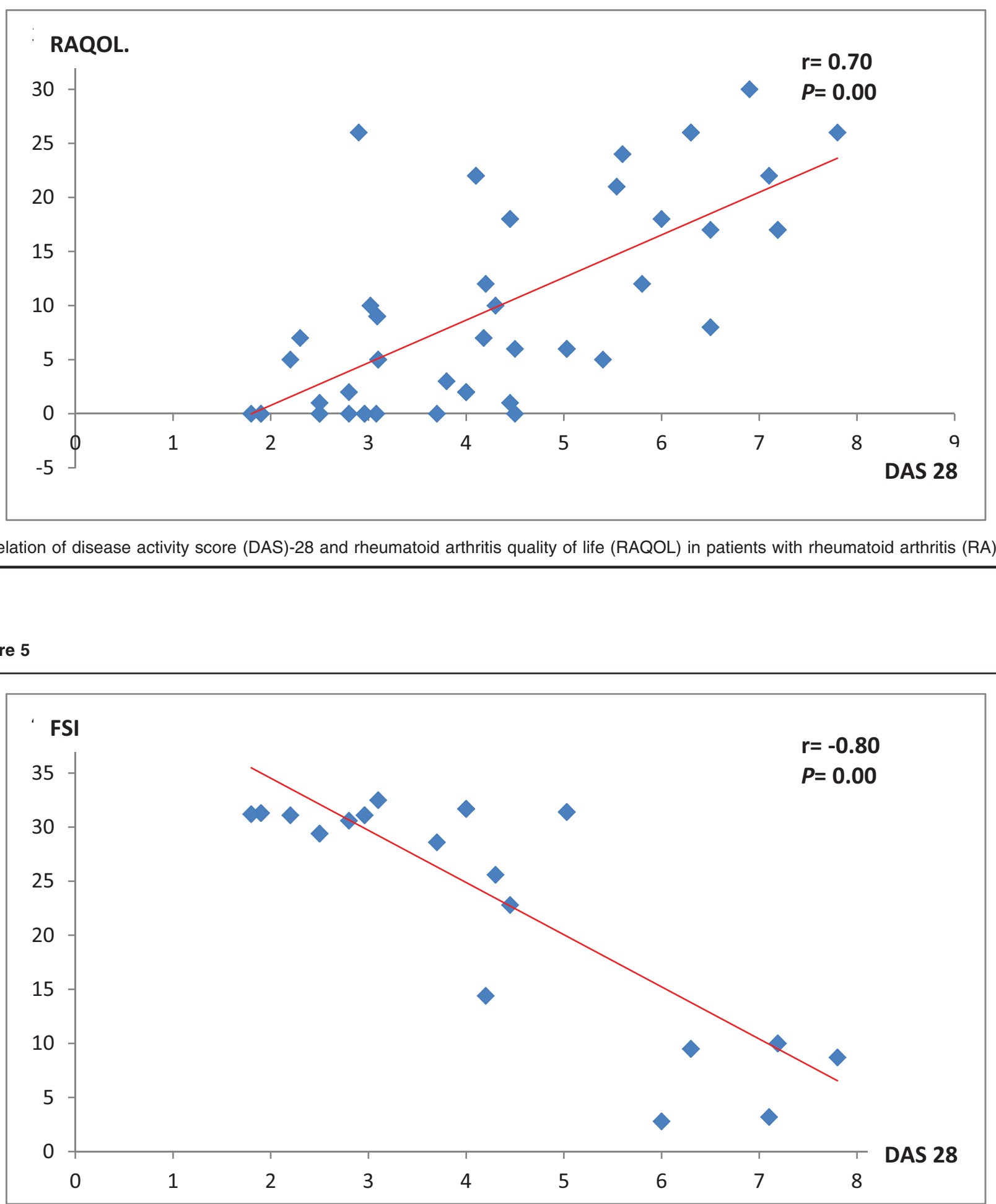

Correlation Between disease activity score (DAS)-28 and Female Sexual Function Index (FSFI) in patients with rheumatoid arthritis (RA).

with high disease activity and limitation of joint mobility.

Moreover, this was consistent with a study performed in Brazil in 2013 which estimated that moderate to severe RA was associated with major functional disability and morbidity, with work and activity impairment increasing with disease severity [19].
The present study found that majority of patients with low disease activity had mild to moderate anxiety based on HAM-A, whereas $75 \%$ of patients with moderate disease activity and 83.3\% of patients on remission had mild anxiety based on Hamilton anxiety scale. DAS-28 score had a positive significant correlation with HAM-A $(P=0.01$, $r=0.46)$. 
Table 1 Correlation between disease activity score-28 with domains of SF-36 in patients with rheumatoid arthritis

\begin{tabular}{lcc}
\hline SF-36 domains & \multicolumn{2}{c}{ DAS-28 } \\
\cline { 2 - 3 } & $r$ & $P$ value \\
\hline Physical function & -0.57 & $<0.001$ \\
Role limitation owing to physical health & -0.69 & $<0.001$ \\
Role limitation owing to emotional problem & -0.58 & $<0.001$ \\
Energy/fatigue & -0.63 & $<0.001$ \\
Emotional well-being & -0.54 & $<0.001$ \\
Social function & -0.61 & $<0.001$ \\
Pain & -0.78 & $<0.001$ \\
General health & -0.62 & $<0.001$ \\
Health change & -0.54 & $<0.001$ \\
\hline
\end{tabular}

Data were expressed in form of $r$, indicating strength of correlation, whereas $P$ value indicates significance of correlation. DAS, disease activity score.

Table 2 Correlation of disease activity score-28 with domains of WHOQOL-BREF

\begin{tabular}{lcc}
\hline WHO quality of life domains & \multicolumn{2}{c}{ DAS-28 } \\
\cline { 2 - 3 } & $r$ & $P$ value \\
\hline General health & -0.58 & 0.001 \\
Physical health & -0.57 & $<0.001$ \\
Psychological health & -0.59 & $<0.001$ \\
Social relations & -0.32 & 0.001 \\
Environmental relations & -0.31 & $<0.001$ \\
\hline
\end{tabular}

Data were expressed in form of $r$, indicating strength of correlation, whereas $P$ value indicates significance of correlation. DAS, disease activity score; WHOQOL-BREF, WHO quality of life.

This is consistent with a study by Scott [20] which found that many patients with RA experienced anxiety and helplessness and a strong correlation between anxiety with the DAS-28.

Another study reported that the prevalence of anxiety in RA cases was higher than that in the normal population and also found that patients with RA are accompanied by anxiety in early stages of the disease [21]. A study by Clarke and Currie [22] reported that anxiety has a significant rate of comorbidity. Another study reported that anxiety is common in RA cases, but the level of anxiety in RA is similar to that in such noninflammatory rheumatological diseases such as osteoarthritis, mechanical lumbar pain, and fibromyalgia [23].

Some authors found in their studies that treatment of accompanying psychiatric disorders reduces disease activity, which means that anxiety has a significant positive correlation with disease activity [24].

In this study, most patients with low disease activity (82\%) and those with moderate disease activity (71\%) were not depressed, whereas majority (85.7\%) of those with high disease activity were depressed based on
Zung self-rating depression score. DAS-28 score had a positive strong significant correlation with Zung score $(P=0.01, r=0.46)$. This is consistent with a study by Smedstad et al. [25] which found highly significant increase in depression in patients with RA compared with the control. Moreover, this results are consistent with another study which found a strong correlation between depressions and the disease activity (DAS-28) [26]. Another study performed by Dickens et al. [27] discovered in a systematic review and meta-analysis of the literature that depression was more frequent in individuals with RA than in healthy individuals. In 2013, another meta-analysis of 72 studies that included 13189 patients with RA found that the prevalence of major depression was $16.8 \%$ [28]. This variation between the last study and our results is that they assessed depression in all patients with RA, but we assessed it in patients with high disease activity.

The RAQOL questionnaire is a specific instrument to measure QOL in patients with RA, where lower scores indicate better QOL (range: 0-30). The present study results of RAQOL questionnaire on patients with RA revealed that DAS-28 has a significant strong positive correlation with QOL of patients with RA ( $r=0.70$, $P=0.00$ ); most patients on remission or with low disease activity showed good QOL and low RAQOL score, and others with high disease activity showed high RAQOL score and bad QOL. This is consistent with a study which reported that disease activity in RA had a negative effect on QOL, which was measured with Rheumatoid Arthritis Quality of Life Scale, a RA-specific measure [29]. Moreover, this is consistent with another study that was conducted on 79 patients with RA in Colombia, where they evaluated QOL by using Quality of life-Rheumatoid Arthritis Scale [30] and demonstrated that RA activity significantly influenced QOL. Similarly, this finding was confirmed in previous studies by Prajs et al. [31].

Sexual functioning is affected in almost all rheumatic diseases. This is owing to multifactorial reasons including disease-related factors as well as therapy. The sexual problems in RA could be owing to physical and psychological factors such as sexual disability, difficulty in assuming certain positions when hip or knee movements are limited, altered body image, and depression. Dyspareunia also affects sexual functioning owing to vaginal dryness, joint pain, and fatigue [32].

This study found that $10(21.7 \%)$ of 46 female patients with RA experience sexual dysfunction, especially 
those with functional disability and with high disease activity, and DAS-28 has a significant strong negative correlation with female sexual functioning index $(r=-0.80, \quad P=0.00)$. Abdel-Nasser and Ali [33] examined 52 patients with RA and reported that sexual dysfunction was present in women in $60 \%$ of the cases.

Prevalence of FSD in patients with RA in a study by $\mathrm{El}$ Miedany et al. [34] ranged from 45 to $62 \%$. A study by Shahar et al. [35] assessed sexual function in women with RA using the FSFI score. They reported a lower prevalence of FSD (29.4\%), but Coskun et al. [36] reported that $68.75 \%$ of Turkish women with RA had a sexual dysfunction according to FSFI score versus 15\% of healthy controls.

In the study by Frikha et al. [37], seven out of 10 women with RA had a sexual dysfunction assessed by FSFI score, and all subscales of FSFI were affected. Another Turkish study found a mean of total score of FSFI in patients with RA (22.6 \pm 9.0$)$, which significantly lower than controls $(34.6 \pm 8.3)$ [38].

In this study, QOL in patients with RA was studied using the SF-36 questionnaire, which is the most widely used generic measure of health status, and our results reported that patients with high disease activity show bad QOL and those with low disease activity and on remission show better QOL. Moreover, we found a significant negative correlation between disease activity and both mental and physical domains of the SF-36, with impairment of all domains of SF36. The most affected domain is pain and role limitation due to physical health, so PCS is more affected than MCS.

In this study, disease activity significantly correlated with both components of SF-36. Significantly high PCS score was found among patients with RA with low DAS-28 and those on remission compared with those with moderate and high DAS-28 $(P<0.001)$. This is consistent with a study which found impairment of all the eight domains of the SF-36 in the patients with RA, where the score of each domain was less than $50 \%$ of its maximum score. Moreover, it is consistent with a study on 26 Egyptian patients with early RA from Sohag, where the QOL was impaired also using the SF-36 measure [39].Birrell et al. [40] studied 86 patients with RA attending specialist clinics and found that impairment of health status was moderate to marked by the SF-36, with significant differences from normal population and chronic disease states such as low back pain. They concluded that it is a practical tool for use in patients with RA.

A study for assessing the QOL in patients with RA used the generic questionnaire WHOQOL-BREF, and the results showed that the more intense the activity of the disease, the worse the perceived QOL of patients with active disease, whereas patients with low disease activity have better QOL perception. The Physical, Psychological and general health domains were the most affected in those with active RA, and it was noticed that all five domains of WHOQOL had significant negative correlations with DAS-28 in this study. This is consistent with a previous study that showed lower QOL in the physical health and psychological domains compared with the mean scores reported by the 23 countries in the WHOQOL group, but QOL in the social relationships and environmental domains was comparable [41].

The results of this study are consistent with a study that reported that patients with RA have significant compromise in their QOL compared with agematched normal healthy population [42], and also consistent with a study which reported that the QOL of patients with RA has been reported to be worse than patients with other chronic diseases like Sjögren' syndrome, asthma/chronic bronchitis, heart disease, hypertension, diabetes mellitus, migraine, and dermatological disease [43].

\section{Conclusion}

This study confirms that RA causes impairment of all aspects of QOL (limitation of physical function, physical disability, and pain), mental health disorders (anxiety and depression), and social, environmental, and also sexual dysfunction, and the disease activity is the most predictor factor in those patients, where this study reported that disease activity (measured by DAS28) negatively correlated with QOL and sexual function and positively correlated with depression and anxiety.

\section{Financial support and sponsorship}

Nil.

\section{Conflicts of interest}

There are no conflicts of interest.

\section{References}

1 Palferman TG. Principles of rheumatoid arthritis control. J Rheumatol Suppl 2003; 67:10-13. 
2 Chorus A, Miedema H, Boonen A, van Der Linden S. Quality of life and work in patients with rheumatoid arthritis and ankylosing spondylitis of working age. Ann Rheum Dis 2003; 62:1178-1184.

3 Vos T, Flaxman AD, Naghavi M, Lozano R, Michaud C, Ezzati M, et al. Years lived with disability (YLDs) for 1160 sequelae of 289 diseases and injuries 1990-2010: a systematic analysis for the Global Burden of Disease Study 2010. Lancet 2012; 380:2163-2196.

4 Wan G, Counte M, Cella D. A framework for organizing health-related quality of life research. J Rehabil Outcomes Meas 1997; 1:31-37.

5 Mathew A, Antony J, Eremenco S, Paul B, Jayakumar B, Philip J. Healthrelated quality of life in rheumatoid arthritis patients in South India. Singapore Med J 2009; 50:800.

6 Kaplan RM, Bush JW. Health-related quality of life measurement for evaluation research and policy analysis. Health Psychol 1982; 1:61.

7 Uhlig T, Loge JH, Kristiansen IS, Kvien TK. Quantification of reduced health-related quality of life in patients with rheumatoid arthritis compared to the general population. J Rheumatol 2007; 34:1241-1247.

8 Yaghoubi A, Tabrizi JS, Mirinazhad MM, Azami S, Naghavi-Behzad M, Ghojazadeh M. Quality of life in cardiovascular patients in Iran and factors affecting it: a systematic review. J Cardiovasc Thorac Res 2012; $4 \cdot 95$

9 Tosa EE, Albu A, Popa M. The effect of physical therapy on the improvement of the quality of life in rheumatoid arthritis patients. Civil Sport 2016; 17:29-34.

10 Uhlig T, Moe RH, Kvien TK. The burden of disease in rheumatoid arthritis. Pharmacoeconomics 2014; 32:841-851.

11 Patrick DL, Deyo RA. Generic and disease-specific measures in assessing health status and quality of life. Med Care 1989; 27:S217-S232.

12 Damiano AM, Steinberg EP, Cassard SD, Bass EB, Diener-West M, Legro $\mathrm{MW}$, et al. Comparison of generic versus disease-specific measures of functional impairment in patients with cataract. Med Care 1995; 33: AS120-AS130.

13 Aletaha D, Neogi T, Silman AJ, Funovits J, Felson DT, Bingham CO, et al. 2010 rheumatoid arthritis classification criteria: an American College of Rheumatology/European 104 League Against Rheumatism collaborative initiative. Ann Rheum Dis 2010; 69:1580-1588.

14 Heinimann K, von Kempis J, Sauter R, Schiff M, Sokka-Isler T, SchulzeKoops $\mathrm{H}$, et al. Long-term increase of radiographic damage and disability in patients with RA in relation to disease duration in the era of biologics. Results from the SCQM cohort. J Clin Med 2018; 7:57.

15 Zeman MN, Scott PJ. Current imaging strategies in rheumatoid arthritis. Am $\mathrm{J}$ Nucl Med Mol Imaging 2012; 2:174.

16 Hussein WA. The quality of life in patients with rheumatoid arthritis in Baghdad, 2017: a cross-sectional study. Int J Med Res Health Sci 2017; 6:20-34.

17 Kojima M, Kojima T, Ishiguro N, Oguchi T, Oba M, Tsuchiya $\mathrm{H}$, et al. Psychosocial factors, disease status, and quality of life in patients with rheumatoid arthritis. J Psychosom Res 2009; 67:425-431.

18 Karpouzas GA, Draper T, Moran R, Hernandez E, Nicassio P, Weisman $\mathrm{MH}$, et al. Trends in functional disability and determinants of clinically meaningful change over time in hispanic patients with rheumatoid arthritis in the US. Arthritis Care Res (Hoboken) 2017; 69:294-298.

19 Da Rocha Castelar Pinheiro P, Khandker R, Sato R, Rose A, Piercy J. Impact of rheumatoid arthritis on quality of life, work productivity and resource utilisation: an observational, cross-sectional study in Brazil. Clin Exp Rheumatol 2013; 31:334-340.

20 Scott DL. Radiological progression in established rheumatoid arthritis. J Rheumatol Suppl 2004; 69:55-65.

21 VanDyke MM, Parker JC, Smarr KL, Hewett JE, Johnson GE, Slaughter JR, et al. Anxiety in rheumatoid arthritis. Arthritis Rheum 2004; 51:408-412.

22 Clarke DM, Currie KC. Depression, anxiety and their relationship with chronic diseases: a review of the epidemiology, risk and treatment evidence. Med J Aust 2009; 190:S54.

23 Hawley D, Wolfe F. Anxiety and depression in patients with rheumatoid arthritis: a prospective study of 400 patients. J Rheumatol 1988; 15:932-941.
24 Bradley LA, Young LD, Anderson KO, Turner RA, Agudelo CA, Mcdaniel LK, et al. Effects of psychological therapy on pain behavior of rheumatoid arthritis patients. Treatment outcome and six-month follow up. Arthritis Rheum 1987; 30:1105-1114.

25 Smedstad L, Vaglum P, Moum T, Kvien T. The relationship between psychological distress and traditional clinical variables: a 2 year prospective study of 216 patients with early rheumatoid arthritis. $\mathrm{Br} \mathrm{J}$ Rheumatol 1997; 36:1304-1311.

26 Guyatt GH. Measurement of health-related quality of life in heart failure. J Am Coll Cardiol 1993; 22:A185-A191.

27 Dickens C, McGowan L, Clark-Carter D, Creed F. Depression in rheumatoid arthritis: a systematic review of the literature with metaanalysis. Psychosom Med 2002; 64:52-60.

28 Matcham F, Rayner L, Steer S, Hotopf M. The prevalence of depression in rheumatoid arthritis: a systematic review and meta-analysis. Rheumatology 2013; 52:2136-2148.

29 Sunar I, Garip Y, Yilmaz O, Bodur H, Ataman S. Disease activity (rheumatoid arthritis disease activity index-5) in patients with rheumatoid arthritis and its association with quality of life, pain, fatigue, and functional and psychological status. Arch Rheumatol 2015; 30:144-150.

30 Cadena J, Vinaccia S, Pérez A, Rico MI, Hinojosa R, Anaya JM. The impact of disease activity on the quality of life, mental health status, and family dysfunction in colombian patients with rheumatoid arthritis. J Clin Rheumatol 2003; 9:142.

31 Prajs K, Fliciński J, Brzosko I, Przepiera-Bedzak H, Ostanek L, Brzosko M. Quality of life and activity of disease in patients with rheumatoid arthritis. InAnnales Academiae Medicae Stetinensis 2006; 52:39-43.

32 Lankveld WV, Ruiterkamp G, Näring G, Rooij DD. Marital and sexual satisfaction in patients with RA and their spouses. Scand J Rheumatol 2004; 33:405-408.

33 Abdel-Nasser AM, Ali El. Determinants of sexual disability and dissatisfaction in female patients with rheumatoid arthritis. Clin Rheumatol 2006; 25:822-830.

34 El Miedany Y, El Gaafary M, El Aroussy N, Youssef S, Ahmed I. Sexual dysfunction in rheumatoid arthritis patients: arthritis and beyond. Clin Rheumatol 2012; 31:601-606.

35 Shahar MA, Hussein H, Sidi H, Shah SA, Mohamed Said MS. Sexual dysfunction and its determinants in Malaysian women with rheumatoid arthritis. Int J Rheum Dis 2012; 15:468-477.

36 Coskun B, Coskun BN, Atis G, Ergenekon E, Dilek K. Evaluation of sexual function in women with rheumatoid arthritis. Urol J 2014; 10:1081-1087.

37 Frikha F, Maazoun F, Ben RS, Snoussi M, Masmoudi J, Nabil MM, et al. Sexual function in married women with rheumatoid arthritis. Presse Med 2011; 40:e521-e527.

38 Yilmaz H, Polat HAD, Yilmaz SD, Erkin G, Kucuksen S, Salli A, et al. Evaluation of sexual dysfunction in women with rheumatoid arthritis: a controlled study. J Sex Med 2012; 9:2664.

39 Al-Fadl EMA, Ismail MA, Thabit M, El-Serogy Y. Assessment of healthrelated quality of life, anxiety and depression in patients with early rheumatoid arthritis. Egypt Rheumatol 2014; 36:51-56.

40 Birrell $F$, Hassell A, Jones $P$, Dawes $P$. How does the short form 36 health questionnaire (SF-36) in rheumatoid arthritis (RA) relate to RA outcome measures and SF-36 population values? A cross-sectional study. Clin Rheumatol 2000; 19:195-199.

41 Skevington SM, Lotfy M, O'Connell KA. The World Health Organization 's WHOQOL-BREF quality of life assessment: psychometric properties and results of the international field trial. A report from the WHOQOL group. Qual Life Res 2004; 13:299-310.

42 Taylor WJ, Myers J, Simpson RT, McPherson KM, Weatherall M. Quality of life of people with rheumatoid arthritis as measured by the World Health Organization Quality of Life Instrument, Short Form (WHOQOL-BREF): Score distributions and psychometric properties. Arthritis Rheum 2004; 51:350-357

43 Strömbeck B, Ekdahl C, Manthorpe R, Wikström I, Jacobsson L. Healthrelated quality of life in primary Sjögren's syndrome, rheumatoid arthritis and fibromyalgia compared to normal population data using SF-36. Scand J Rheumatol 2000; 29:20-28. 